\title{
CPW-fed Wideband Antenna with U-shaped Ground Plane
}

\author{
Shagun Maheshwari ${ }^{\mathrm{a}}$, Priyanka Jain ${ }^{\mathrm{a}}$, Archana Agarwal ${ }^{\mathrm{b}}$ \\ ${ }^{a}$ Electronics and Communication, I.T.M. University, Gurgaon, India \\ ${ }^{b}$ Electronics and Communication, Sangam University, Bhilwara, India
}

\begin{abstract}
This paper proposes the design of CPW-fed wideband antenna with U-shaped ground plane. The proposed antenna is a simple printed antenna, which is fed by a $50 \Omega$ CPW line. The Antenna has a compact size of $13 \mathrm{~mm} \times 25 \mathrm{~mm}$. To obtain wide bandwidth, a slot is cut in ground plane and radiating patch is modified. The proposed antenna yields the operating frequency range from $7.3 \mathrm{GHz}$ to $15.1 \mathrm{GHz}$, which offers the bandwidth of 7.79GHz. Simulation has been performed by using CST Microwave Studio Software. This frequency range satisfies the system requirements for Narrowband PCS Services, Satellite, Cellular Phone, Domestic Public Land Mobile Communication and International Public Broadcasting applications.
\end{abstract}

Index Terms: Coplanar Waveguide (CPW), Wideband (WB), Bandwidth, Microstrip Patch Antenna, Feed line.

(C) 2014 Published by MECS Publisher. Selection and/or peer review under responsibility of the Research Association of Modern Education and Computer Science

\section{Introduction}

Microstrip patch antennas are gaining popularity because of their advantages of low profile; low weight; low cost; easy fabrication and easy integration ability with other microwave circuit components [1] and are used widely in wireless communication systems [2-7]. Besides these advantages microstrip patch antenna has some major drawbacks that are of narrow bandwidth and low gain. Many techniques and efforts have been made to achieve wideband for the patch antenna [8-12]. Normally wideband antennas occupy larger space compared to multiband antennas in the applications. They also achieve higher gain through array configuration. Therefore, wideband antennas are mostly applicable in indoor or outdoor base station applications rather than mobile handsets or notebook computers. Wideband antenna must satisfy VSWR (or return loss) requirement within the desired frequency bands and with this it also must have some additional characteristics such as high gain and high isolation between the antenna elements for base station applications.

In this paper, Coplanar Waveguide Grounded (CPWG) transmission line is used, which is a type of electrical transmission line and fabricated using printed circuit board technology. It is used to convey microwave-

* Corresponding author.

E-mail address: 
frequency signals. For printed antenna structures, feed line is one of the important components and coplanar waveguide is type of the feed line which is becoming popular. On large scale, CPW- fed antennas have been studied [13-14]. A coplanar waveguide consists a dielectric substrate slab on which a metallic strip is deposited with two narrow metallic strip adjacent to it on same side. This coplanar waveguide is uniplanar, which implies that all conductors are on the same side of the substrate [15].

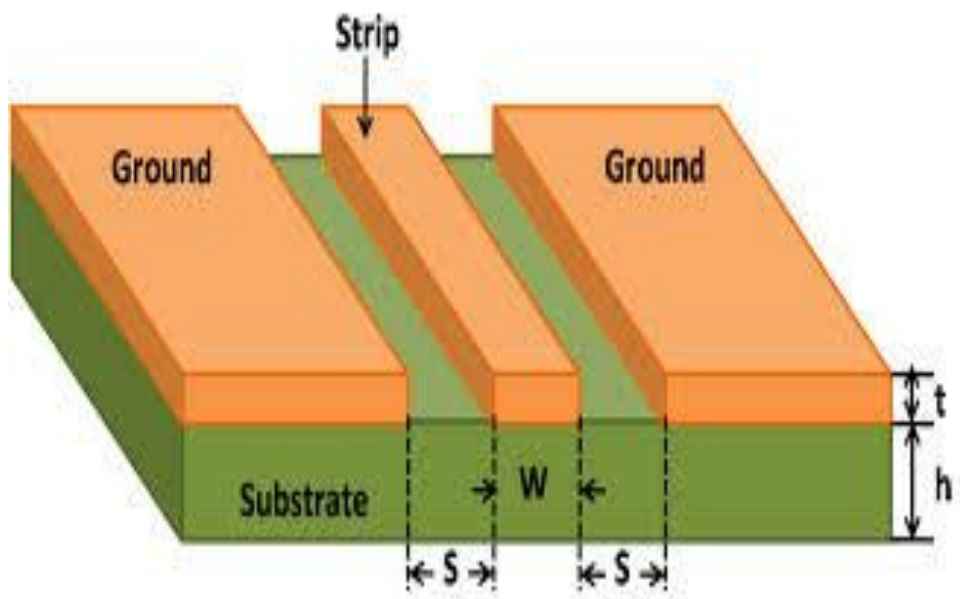

Fig. 1. Geometry of Coplanar Waveguide feed line [15]

CPW Feeding became popular because of their manufacturing advantages, simple configuration, repeatability, low cost and some characteristics such as low radiation loss, low dispersion and ability of integration with active solid-state devices besides wider bandwidth, and better impedance matching. They also allow easy mounting and integration with other microwave integrated circuits and RF frequency devices [16]. This proposed antenna is analyzed by using CST (Computer Simulation Technology) EM Solver Simulation Software.

The design of antenna is proposed by the modification in ground and radiating patch, which offers the impedance bandwidth ranging from $7.3 \mathrm{GHz}$ to $15.1 \mathrm{GHz}$. This frequency range is used for following technologies:

Table 1. Operating bands and corresponding frequency ranges for proposed Antenna

\begin{tabular}{ll}
\hline Technology & Frequency $(\mathrm{GHz})$ \\
\hline Digital radio communication & $7.1-7.7$ \\
Cellular Telephones & $8-8.81$ \\
Domestic Public land mobile communication & $8.81-9.01$ \\
Narrowband PCS services & $9.403-9.4035$ \\
International public Broadcasting & $9.4035-9.52$ \\
Maritime Communication & $9.52-9.60$ \\
Public Safety & $9.60-12.40$ \\
Satellite-Ku band & $12-14$ \\
\hline
\end{tabular}

The remaining paper is organized as follows. Section II provides the antenna design for modified U-shaped ground plane CPW-fed wideband antenna. Section III defines simulation results of CPW-fed wideband antenna. 
Section IV concludes the design of CPW-fed wideband antenna with modified U-shaped ground plane.

\section{Antenna design}

The proposed antenna for wideband is designed by modification in rectangular patch antenna using CPW-fed technique. The geometry of rectangular patch antenna using CPW-fed technique is shown in Fig. 2. Firstly, the rectangular patch antenna is designed on substrate of $13 \mathrm{~mm} \times 25 \mathrm{~mm} \times 1.6 \mathrm{~mm}$. The dimensions of ground plane are: $\mathrm{W} 1=7 \mathrm{~mm}, \mathrm{~L} 1=10 \mathrm{~mm}$ and of patch are: $\mathrm{W} 2=10 \mathrm{~mm}, \mathrm{~L} 2=7.5 \mathrm{~mm}$. The width and length of feed line is: $\mathrm{W} 3=4 \mathrm{~mm}, \mathrm{~L} 3=12 \mathrm{~mm}$ for impedance of $50 \Omega$ and location of discrete port is: $\mathrm{X}=-3.5 \mathrm{~mm}$ and $\mathrm{Y}=-15 \mathrm{~mm}$.

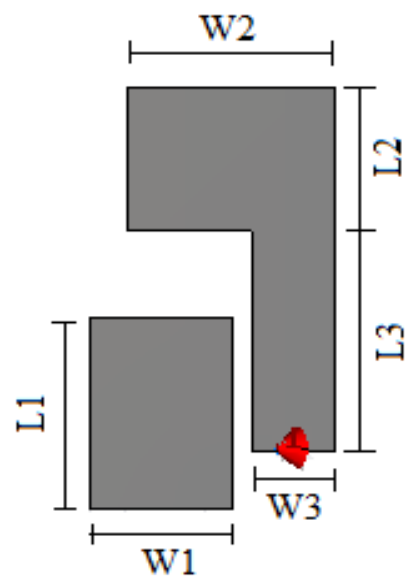

Fig. 2. Geometry of rectangular patch Antenna using CPW-fed

Later, the ground plane is modified in U-shape using the technique of slotting, with slot of dimension: $\mathrm{W}_{\mathrm{S}}=3 \mathrm{~mm}, \mathrm{~L}_{\mathrm{S}}=6 \mathrm{~mm}$ as shown in Fig. 3 . The width $\mathrm{W} 2$ of patch and $\mathrm{W} 3$ of feed line is reduced from $10 \mathrm{~mm}$ to $7 \mathrm{~mm}$ and $4 \mathrm{~mm}$ to $3 \mathrm{~mm}$ respectively. Also the dimensions of patch is optimized to $\mathrm{W} 2^{\prime}=7 \mathrm{~mm}$ and $\mathrm{W} 3^{\prime}=3 \mathrm{~mm}$ to obtain a wide bandwidth as shown in Fig. 3.

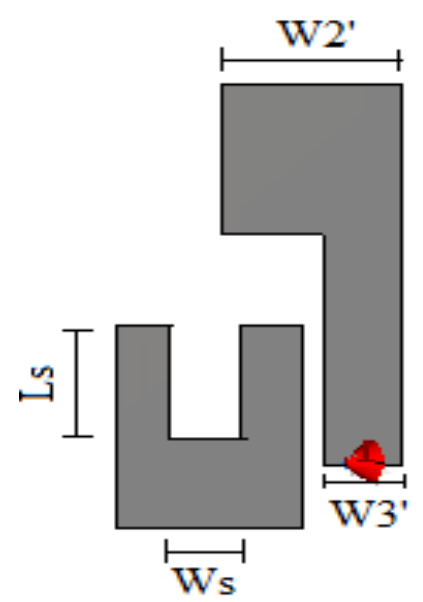

Fig. 3. Geometry of modified U-shaped ground plane CPW-fed Wideband antenna 


\section{Simulation Results}

The simulated result of the normal patch antenna shows that the $-10 \mathrm{~dB}$ impedance bandwidth is $5.969 \mathrm{GHz}$, which is from $7.88 \mathrm{GHz}$ to $13.851 \mathrm{GHz}$. The Return loss vs. Frequency curve for rectangular patch antenna is shown in Fig. 4.

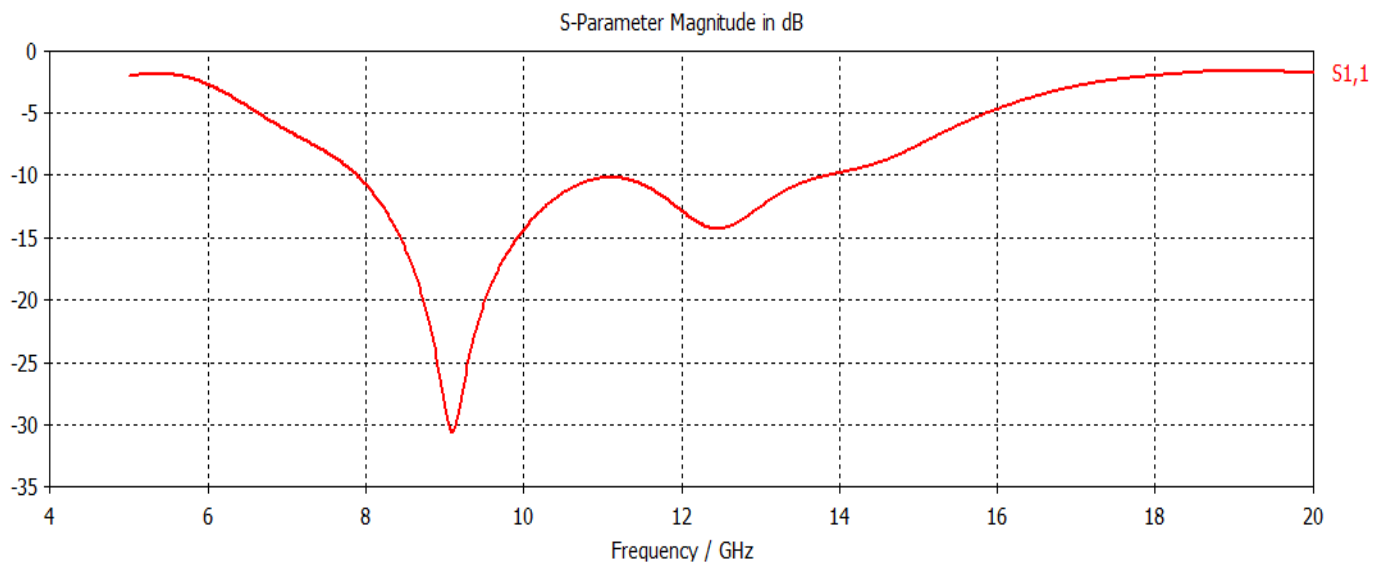

Fig. 4. Return loss vs. Frequency curve for rectangular patch antenna using CPW-fed

The modifications in ground plane is done by cutting a rectangular slot of different lengths, which provide the wide bandwidth. Return loss vs. Frequency curve for varying the length of rectangular slot in ground plane is shown in Fig. 5.

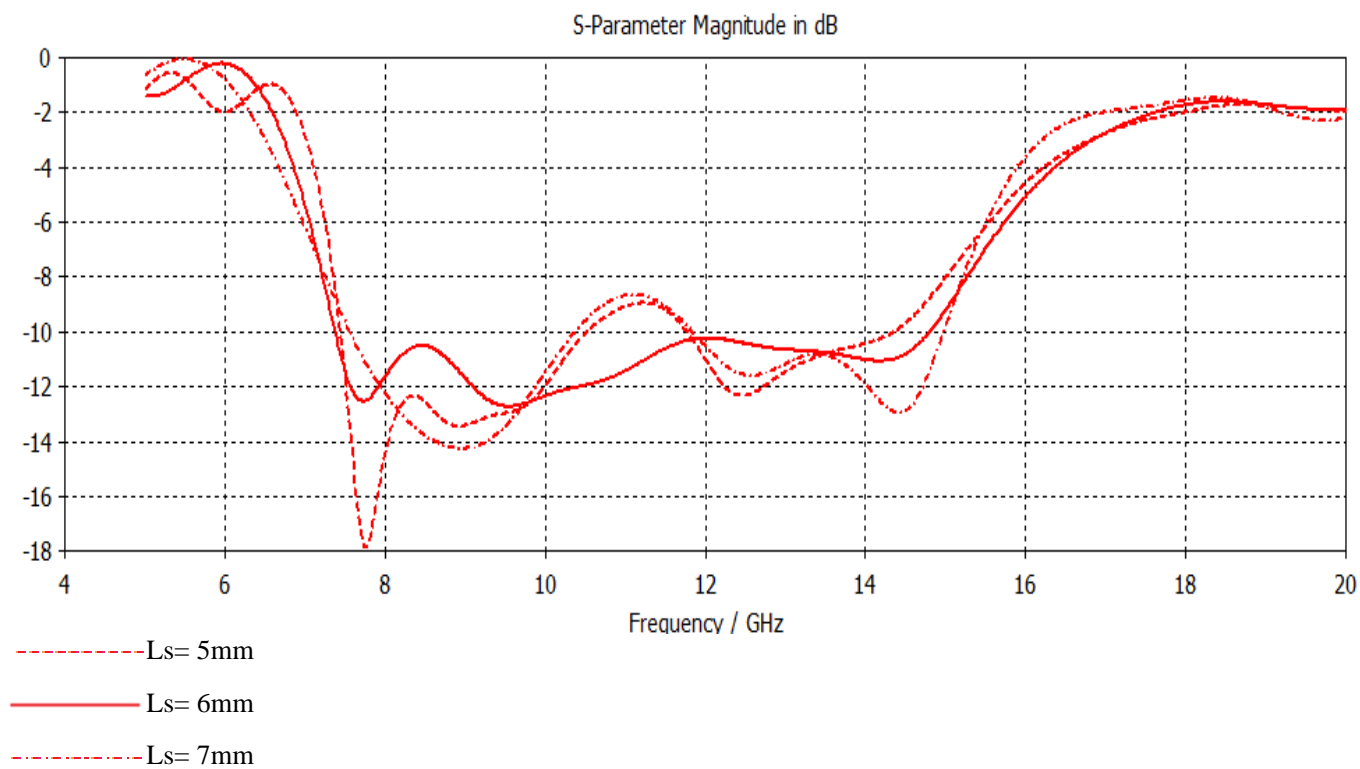

Fig. 5. Return loss vs. Frequency curve for varying the length of rectangular slot in ground plane 
After the modifications in ground plane and radiating patch we get operating frequency ranging from $7.3 \mathrm{GHz}$ to $15.1 \mathrm{GHz}$, which offers the bandwidth of $7.79 \mathrm{GHz}$. The Return loss vs. Frequency curve for modified U-shaped ground plane CPW-fed wideband antenna is shown in Fig. 6.

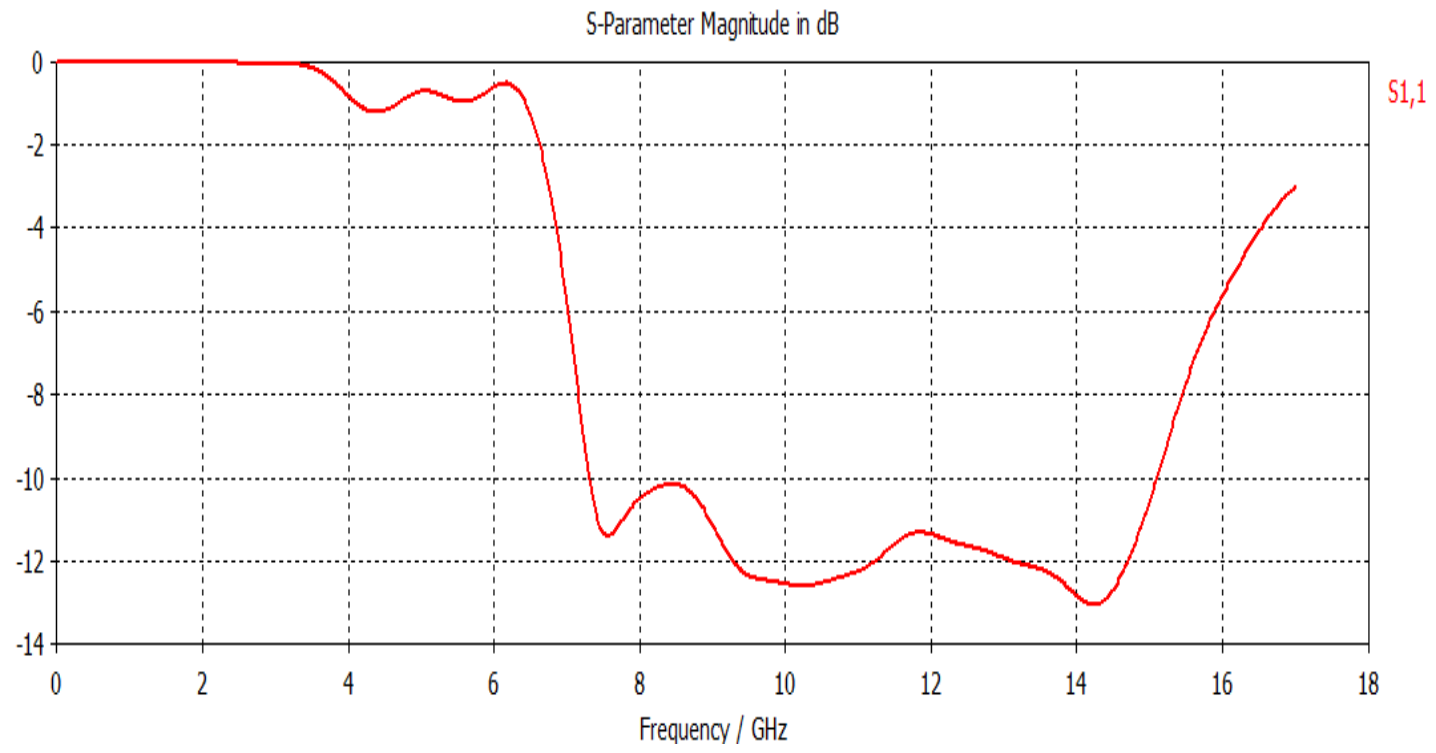

Fig. 6. Return loss vs. Frequency curve for modified U-shaped ground plane CPW-fed wideband antenna

Fig. 7 illustrates the simulated voltage standing wave ratio (VSWR) for the proposed CPW-fed wideband antenna. VSWR of the antenna is closely related to the return loss. Return loss below $-10 \mathrm{~dB}$ is also represented by VSWR from 1 to 2 in the frequency range of $7.3 \mathrm{GHz}$ to $15.1 \mathrm{GHz}$.

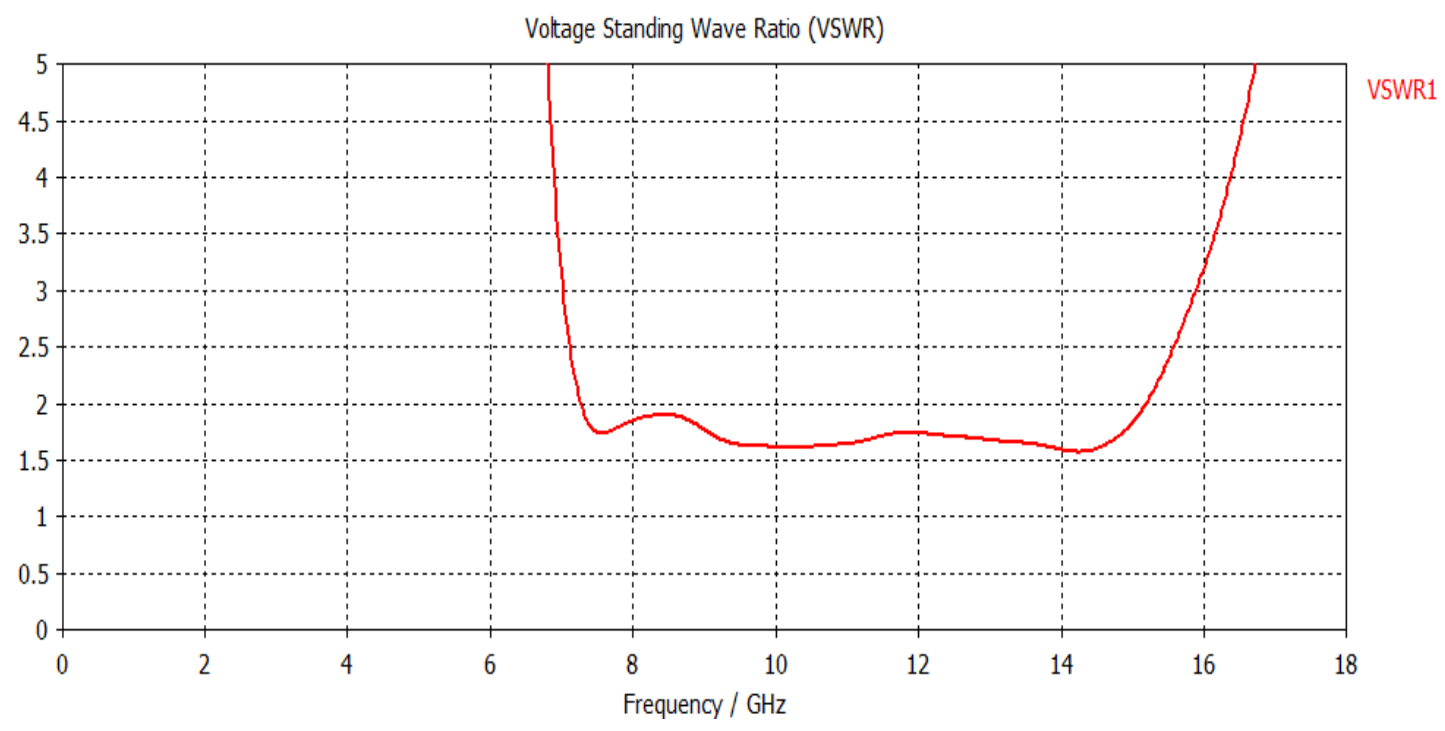

Fig. 7. The voltage standing wave ratio (VSWR) curve for the proposed CPW-fed wideband antenna 
Fig.8 illustrates the simulated radiation pattern for the proposed CPW-fed wideband antenna at central frequency $11.208 \mathrm{GHz}$. Radiation pattern shows the graphical representation of the antenna parameters with respect to space.

\section{Farfield Directivity Abs (Phi=90)}

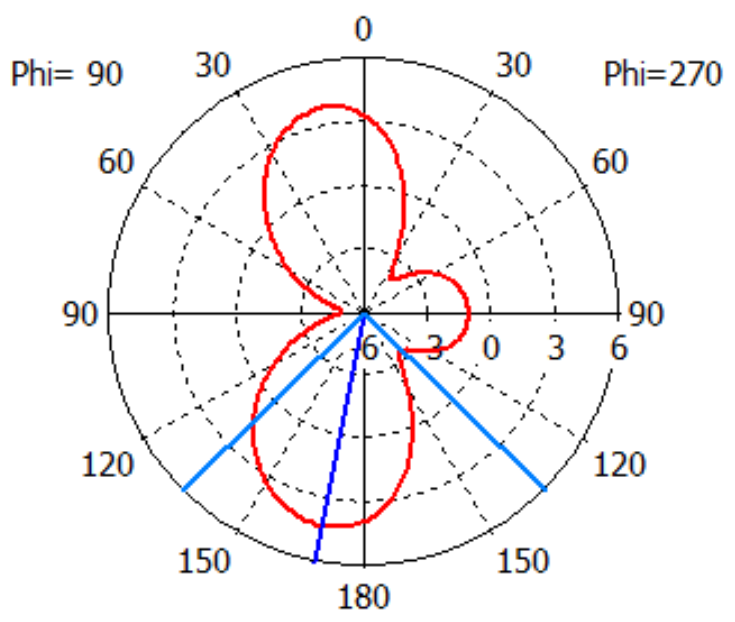

Theta / Degree vs. dBi

Fig.8. Radiation Pattern for proposed CPW-fed wideband antenna

\section{Conclusion}

The CPW-fed wideband antenna with U-shaped ground plane is designed to obtain the wide frequency of spectrum. Ground plane is cut in $U$ shape and radiating patch is optimized with dimension variations. This proposed antenna offers wide bandwidth of $7.79 \mathrm{GHz}$. The operating frequency range is from $7.3 \mathrm{GHz}$ to $15.1 \mathrm{GHz}$, which is used in many applications such as: Digital Radio Communication, Cellular Telephones, Narrowband PCS Services, and International Public Broadcasting \& Satellite Communication.

\section{References}

[1] C. A. Balanis, Antenna Theory and Design, 3rd Edition.

[2] J. R. James and P. S. Hall, Handbook of Microstrip Antennas, Vol. 1, Peter Peregrinus Ltd., London, 1989.

[3] R. Garg, P. Bhartia, I. J. Bahl and A. Ittipiboon, Microstrip Antenna Design Handbook, Artech House, 2001.

[4] F. Yang, X-X Zhang, X. Ye and Y. Rahmat-Samii, "Wide- Band E-Shaped Patch Antennas for Wireless Communications", IEEE Trans. Antennas and Propagat., vol. AP-49, pp. 1094- 1100, 2001.

[5] E. S. Angelopoulos, A. Z. Anastopsoulos, D. I. Kaklamani, A. A. Alexandridis, F. Lazarakis and K. Dangakis, "Circular and Elliptical CPW-fed Slot and Microstrip-fed Antennas for Ultrawideband Applications", IEEE Antennas and Wireless Propagation Letters, vol. 5, pp. 294 - 297, 2006.

[6] X. Jing, Z. Du and K. Gong, "A Compact Multiband Planar Antenna for Mobile Handsets", IEEE Antennas and Wireless Propagation Letters, vol. 5, pp. 343 - 345, 2006. 
[7] Sukhmeet Singh Kalsi, Vibha Rani Gupta, "Slotted Planar Microstrip Antenna for HIPERLAN/2 Application,” IEEE Applied Electromagnetics Conference, Kolkata, India, 14-16 December 2009.

[8] T. M. Au, K. F. Tong and K. M. Luk, "Characteristics of aperture coupled co-planar microstripsubarrays," IEE Proceedings: Microwave, Antennas and Propagation, vol. 144, no. 2, pp. 137-140, 1997.

[9] C. L. Mak, K. M. Luk, K. F. Lee and Y. L. Chow, "Experimental study of a microstrip patch antenna with an L-shaped probe," IEEE Transactions on Antennas and Propagation, vol. 48, no. 5, pp. 777-783, 2000.

[10] Y. X. Guo, A. K. Shackelford, K. F. Lee and K. M. Luk, "Broadband quarter-wavelength patch antennas with a U-shaped slot," Microwave and Optical Technology Letters, vol. 28, no. 5, pp. 328-330, 2001.

[11] A. K. Shackelford, K. F. Lee, K. M. Luk and R. C. Chair, "U-slot patch antenna with shorting pin," Electronics Letters, vol. 37, no. 12, pp. 729-730, 2001.

[12] C. L. Mak, R. C. Chair, K. F. Lee, K. M. Luk and A. A. Kishk, "Half U-slot patch antenna with shorting wall," Electronics Letters, vol. 39, no. 25, pp. 1779-1780, 2003.

[13] K.L.Wong, Compact and Broadband Microstrip Antennas, Wiley, 2002.

[14] G. Kumar and K. P. Ray, Broadband Microstrip Antennas, Artech House, Boston, 2003.

[15] Leena Varshney, Vibha Rani Gupta, Harish kumar, Priyadarshi Suraj, "CPW-Fed Broadband Microstrip Patch Antenna," International Journal of Advanced Engineering and Application, Issue. 172, Jan 2011.

[16] Benson, F. A. and T. M. Benson, "Fields Waves and Transmission Line", Chapman \& Hall, 1991.

\section{Author(s) Profile}

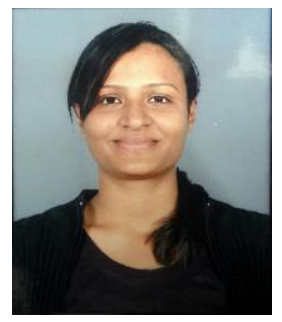

Shagun Maheshwari received her bachelor of engineering degree in Electronics \& Communication Engineering from ITM, Bhilwara, under University of Rajasthan in 2013 with honours and now is a M.Tech. student in the ITM University, Gurgaon. Her area of interest lies in the field of antenna designing and microwave engineering.

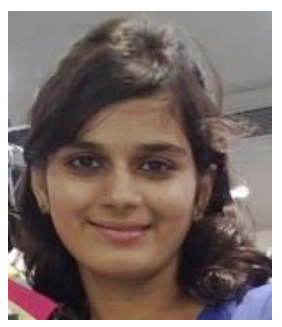

Priyanka Jain received her bachelor of engineering degree in Electronics \& Communication Engineering from ITM, Bhilwara, under University of Rajasthan in 2013 with honours and now is a M.Tech. student in the ITM University, Gurgaon. Her area of interest lies in the field of antenna designing and microwave engineering.

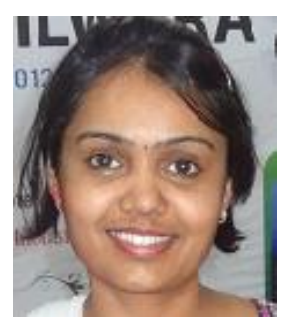

Archana Agrawal is B.E., M.Tech, and Ph.D. in the field of Electronics and Communication Engineering. She is working as a professor in the Department of Electronics and Communication at Sangam University and has a total teaching experience of 10 years. Her area of interest lies in the field of antenna designing and microwave engineering. 